\title{
ERP abnormalities during semantic processing in schizophrenia
}

\section{Citation}

Adams, Jane, Steven F. Faux, Paul G. Nestor, Martha Shenton, Brian Marcy, Scott Smith, and Robert W. McCarley. 1993. ERP Abnormalities During Semantic Processing in Schizophrenia. Schizophrenia Research 10, no. 3: 247-257. doi:10.1016/0920-9964(93)90059-r.

\section{Published Version}

doi:10.1176/ajp.153.10.1347

\section{Permanent link}

http://nrs.harvard.edu/urn-3:HUL.InstRepos:28499627

\section{Terms of Use}

This article was downloaded from Harvard University's DASH repository, and is made available under the terms and conditions applicable to Other Posted Material, as set forth at http:// nrs.harvard.edu/urn-3:HUL.InstRepos:dash.current.terms-of-use\#LAA

\section{Share Your Story}

The Harvard community has made this article openly available.

Please share how this access benefits you. Submit a story.

\section{Accessibility}


Published in final edited form as:

Schizophr Res. 1993 October ; 10(3): 247-257.

\title{
ERP abnormalities during semantic processing in schizophrenia*
}

\author{
Jane Adams ${ }^{1}$, Steven F. Faux ${ }^{2}$, Paul G. Nestor, Martha Shenton, Brian Marcy, Scott Smith, \\ and Robert W. McCarley \\ Department qf Psychiatry. Harvard Medical School and the Brockton VAMC and Massachusetts \\ Mental Health Center, Brockton, MA 02401, USA
}

\section{Abstract}

To examine the neurophysiological and cognitive characteristics of thought disturbance in schizophrenic patients, we examined the amplitude, latency, and topography of a specific eventrelated brain potential (ERP), the N400, which is elicited by semantically incongruent words and phrases. Twelve chronic schizophrenic patients and twelve age-matched control subjects read sentences presented visually that had either semantically correct (e.g., 'People pray in their local church') or incorrect endings (e.g., 'Every Sunday morning people pray in their local nest'). Relative to normal controls, schizophrenic patients had significantly reduced N400 amplitude and increased latency to semantically anomalous endings. Additionally, a late positive component which follows the N400 was significantly reduced in amplitude in schizophrenic patients. However, patients and controls did not differ significantly in terms of the topographical distribution of either the N400 or its late positive potential, examined at 28 electrode sites. Thus, N400 topography in schizophrenic patients was not accompanied by the asymmetry which frequently characterizes the well known auditory P300 disturbance in schizophrenic patients. We concluded that these findings may reflect a profound disturbance in attentional processes in chronic schizophrenia.

\section{Keywords}

Event-related potential; Topography; Attentional disturbance (schizophrenia)

\section{INTRODUCTION}

\begin{abstract}
A hallmark of schizophrenia is a disturbance in thought whereby discourse is often contaminated by semantically incorrect words or phrases. This is evidenced clinically by such distinct symptoms as loose associations, word salad, circumstantiality, and tangentiality. Although the cognitive mechanisms of schizophrenic thought disorder have been extensively studied (Andreasen, 1979a,b, 1986; Johnson and Holzman, 1979; Holzman et al., 1986) the extent to which this disturbance reflects a specific impairment in semantic processing or may be attributable to a more general dysfunction in attentional processes is unclear. Similarly, the neurobiological basis for thought disturbance has yet to be fully elucidated, although recent evidence from both event-related potential (ERP) and magnetic resonance imaging (MRI) studies point to a left temporal lobe abnormality (McCarley et al., 1989; Shenton et al., 1992).
\end{abstract}

\footnotetext{
*Partial findings were presented at EPIC IX, Noordwijk, The Netherlands, May 28-June 3, 1989.

(C) 1993 Elsevier Science Publishers B.V. All rights reserved

Correspondence to: R.W. McCarley, Dept of Psychiatry 116A, VA Medical Center, Brockton, MA 02401, USA..

${ }_{1}^{1}$ Currently at Department of Psychology, University of Massachusetts, Boston, MA 02125, USA.

${ }^{2}$ Currently at Department of Psychology, Drake University, Des Moines, IA 50325, USA.
} 
To help elucidate some of the neurophysiological and cognitive characteristics of thought disturbance in schizophrenia, we adopted in this current investigation a well-studied ERP paradigm that has been demonstrated to be highly sensitive to semantic incongruities in healthy controls (Kutas and Hillyard, 1980, 1984; Kutas et al., 1984, 1987). In this paradigm, sentences are typically presented visually, one word at a time, with the final word of the sentence being either semantically congruent or semantically incongruent. In healthy subjects, nonsensical endings (e.g., 'Every Sunday morning people pray in their local nest') evoke a late negative, robust ERP component occurring 400 ms post stimulus, known as the N400, whereas a small to non-existent N400 is elicited by semantically congruent endings (e.g., 'People pray in their local church'). Other studies using word pairs (Bentin et al., 1985) have provided additional evidence that the N400 is particularly sensitive to semantic relationships, with the N400 inversely related to the degree of semantic priming: large potentials are elicited by semantically unrelated word pairs (e.g., doctor-bread) and small potentials by semantically related word pairs (doctor-nurse). Also of importance is that the $\mathrm{N} 400$ is typically followed by a late positive component, occurring approximately 500-700 ms post stimulus, which is considered to be a member of the P300 family, presumably reflecting decision making (Kutas et al., 1987).

In schizophrenia, the extent to which the N400 amplitude will vary as a function of semantic incongruency is unclear. We (Adams et al., 1989; McCarley et al., 1991) have reported preliminary evidence demonstrating that schizophrenic patients show a significant reduction in N400 amplitude to semantically incongruent sentence endings. This reduction, however, was not specific to semantic processing per se, as these same patients also show reduced amplitude for the late positive component following N400. On the other hand, Mitchell et al. (1991) found that only N400, but not the subsequent late potential, varied as a function of experimental task demands involving semantic processing. Yet even in this study, because the semantic task was more difficult than the physical task, the N400 amplitude reduction may have been more related to these differences in task difficulty (which presumably influence attentional demand) than to semantic processing per se. Complicating matters even further are that other studies using word pair tasks have consistently found latency but not amplitude differences in N400 in schizophrenic patients (Grillon et al., 1991; Hokama et al., 1990).

Topographical distribution may also represent an another important variable that might distinguish N400 from other schizophrenic-related ERP abnormalities. For example, we have reported a P300 topographic asymmetry in chronic schizophrenia in four separate studies, including those of patients off medication, using the auditory 'odd ball' paradigm (Morstyn et al., 1983; Faux et al., 1988 a,b, 1993). This topography is characterized by a significant reduction in left temporal scalp region voltages, relative to those of the right temporal scalp region. However, it remains unclear whether the auditory P300 asymmetry in schizophrenia may be specific to auditory processing or extend to the visual modality and semantic processing, as reflected by N400. Of note is that in healthy subjects the auditory P300 and the visual N400 have different topographic distributions, with the former symmetrically distributed and the latter with a centro-parietal distribution with slightly larger voltages over the right than left scalp regions (Kutas et al., 1987; Fischer et al., 1983). No study to our knowledge has examined the topography of the $\mathrm{N} 400$ and its subsequent late positive potential in schizophrenic patients.

The purpose of the present investigation is twofold. The first goal is to determine if findings of previous studies, including our own preliminary work, can be confirmed by examining the N400 and its late positive component to semantically incongruent sentences using the classic Kutas paradigm in schizophrenic patients. The second goal is to analyze the topographic distribution of the N400 and its late positive component using a 28 electrode set (10-20 electrodes +8 additional electrodes), and to determine its similarity or difference with the P300. 


\section{METHODS AND PROCEDURES}

\section{Subjects}

Twelve right-handed neuroleptically medicated male inpatients with schizophrenia and 12 right-handed healthy normal controls ( 10 male and 2 female) participated. Patients were interviewed with the SADS (Spitzer et al., 1977) by two raters (MES and RWM), who independently assigned DSM-IIIR (American Psychiatric Association, 1987) and RDC (Spitzer et al., 1977) diagnoses. Patients were selected based upon consensus of the diagnosticians. Mean chlorpromazine equivalent dose of the schizophrenics was $881 \mathrm{mg}$. Mean duration of illness was 21.3 years. Scores on the Scale for the Assessment of Negative Symptoms (SAN; Andreasen, 1981) and the Scale for the Assessment of Positive Symptoms (SAPS; Andreasen, 1984) were available for 10 of the 12 patients. Mean ratings were 11.3 on the SANS and 12.1 on the SAPS.

The following additional criteria for subject selection were used: age range of 25-55; no history of ECT, neurological illness, drug abuse, or alcohol abuse (DSM-IIIR criteria); and no medications which would grossly affect the EEG (e.g., reserpine or barbiturates). Subjects with visual impairments or projected verbal IQs (based on the WAIS-R information sub-scale) below 85 were not selected. For their participation, patient subjects were paid $\$ 7.50 / \mathrm{h}$ or the equivalent in institutional store coupons.

Normal control subjects were drawn from hospital staff and the community; they met the same exclusion criteria as the patient group, and had no personal or family history of psychiatric illness. Control subjects were paid $\$ 7.50 / \mathrm{h}$ for their participation.

\section{Task stimuli}

The stimuli and procedures for the present study were directly adapted from those of Kutas, Neville and Holcomb (1987). The sentences were developed and standardized on young children and are appropriate for young or impaired subjects, Stimuli were constructed from 80 sentence final words which were highly constrained by the preceding sentence context (cloze probability $>0.85$; semantically congruent). Stimulus materials were randomly rearranged in a manner such that half of the final words were semantically correct and half were semantically incorrect (cloze probability $<0.01$ ). Individual words were sequentially presented on a video monitor with subjects seated at approximately 1 meter from the screen (stimuli subtended 1 degree of visual angle). ERPs were collected only following the final words.

\section{Task procedures}

Prior to the actual task, subjects were first given 5 practice sentences to verify task understanding and performance accuracy. The practice task and core task were self-paced with the subject pressing a button when ready for sentence presentation. Each word of the sentence was displayed for $250 \mathrm{~ms}$ with an interword interval of $1 \mathrm{~s}$. The final word of the sentence was cued by a period for punctuation. After a $2 \mathrm{~s}$ delay following sentence presentation, the screen prompted the subject to indicate the sensibility of the sentence. A 'yes' response indicated the sentence was congruent; 'no' signified incongruent. Subjects responded by pressing the left button for 'yes' and right for 'no' (counterbalanced between subjects). Responses were monitored by an assistant who sat behind the subject. When necessary, subjects were reinstructed. The initiation of each sentence was self-paced, but was typically $2-3 \mathrm{~s}$ after the response to the previous sentence. Routinely, breaks were given after every 15 sentences. As described above, a total of 80 sentences were delivered per session ( 40 semantically congruent, 40 semantically incongruent). 


\section{Recording procedures}

Evoked potentials (ERPs) were recorded from 28 tin plate scalp electrodes referred to linkedears using an Electra-Cap International, Inc. electrode cap. Scalp electrode placements included all electrodes in the International 10-20 system with 8 additional interpolated electrodes. The $\mathrm{Fpl}, \mathrm{Fp} 2$ and $\mathrm{Cz}$ sites were located by precise International 10-20 measurements, and all other electrodes were positioned automatically at standard relative distances. The cap contained the following interpolated electrodes: FTCl/2, TCPI/2, CPI/2, PO1/2. FTC1 was placed at the intersection between F3-T3 and C3-F7; TCPl was placed between C3-T5 and P3-T3; CPl and PO1 were placed at the midpoints of the diagonals formed by Cz-P3 and Pz-01, respectively. Electrodes were placed at homologous sites on the contralateral side. Vertical EOG was recorded using right eye supra- and infra-orbital electrodes. Horizontal EOG was recorded from electrodes at the right and left external canthi. EOG contamination was corrected with the use of regression based and subject unique weighting coefficients (Semlitsch et al., 1986). Electrode impedance was maintained at less than $4 \mathrm{k} \Omega$. The EEG was filtered using a bandpass of 0.15 to $40 \mathrm{~Hz}$ (Neuroscience, Inc. EEG amplifiers: $36 \mathrm{~dB}$ /octave rolloff for low-pass and 6 $\mathrm{dB} /$ octave for high-pass). Single trial epochs were digitized and stored on a hard disk, with archival storage on tape. ERP averages for each channel were constructed from $256 \mathrm{~ms}$ samples over a $1000 \mathrm{~ms}$ time interval. Sampling began $100 \mathrm{~ms}$ prior to stimulus presentation, and the average of this prestimulus interval established the baseline. Single trial epochs from any channel which had voltages in excess of $\pm 50 \mu \mathrm{V}$ were excluded.

Data were averaged over trials for semantically congruent final words and semantically incongruent completion final words. During the averaging of ERP data from individual trials, artifact rejection criteria were imposed to reject trials with eyeblink or movement artifact. When this resulted in average based on less than 18 sentences per condition, subjects were rerun using an independent set of sentences. This was necessary for 3 subjects in each group. Our results are based on an average of 33.9 trials/condition for the schizophrenics and 33.6 trials/condition for the normal controls. Unless otherwise specified, all waveform analyses, as in most other N400 studies, were taken from the difference between the semantically incongruent ERP minus the semantically congruent condition ERP.

The N400 peak component latency was defined as the data point at the Cz electrode with the largest negative voltage between 300 to $500 \mathrm{~ms}$. The time interval for amplitude integration was defined as peak component latency plus or minus $50 \mathrm{~ms}$. Since groups appeared to differ in the latency of the N400 (at CZ: normal controls $=368.9$ f $34.3 \mathrm{~ms}$; schizophrenics $=393.1$ $+23.3 \mathrm{~ms}, \mathrm{t}(22)=2.02, \mathrm{p}<0.056), \mathrm{N} 400$ mean integrated amplitude was measured as the mean voltage between 319-419 ms in normal controls and between 343-443 ms in schizophrenics. These time-windows captured the descending phase and nadir of the N400 component in most subjects. Similarly, the late positive peak component latency was defined as the largest positive voltage between 500-900 ms at Cz. Time interval for amplitude integration in the late positive component was determined by peak component latency plus or minus $100 \mathrm{~ms}$ in the normal control group. Period of integration for this late positive component was twice that of the N400 integration period, because inspection of the grand-averaged late positive component suggested that its 'rise/fall' duration was approximately twice that of the N400 component.

The next step in the analysis was to examine the voltage topography using color-coded maps of the voltages at the 28 scalp electrodes (Duffy, 1982). Color topographic maps were interpolated using a four point nearest-neighbor algorithm (Buchsbaum et al., 1982). We then examined group median differences as a function of the rank-order at each site using a nonparametric Mann-Whitney Z-transform significance probability map (SPM) (Duffy, Bartels, and Burchfiel, 1981) to determine the scalp region of maximal statistical separation between schizophrenics and normal controls; the values at each of the 28 electrodes were then interpolated to form a topographic map, using the same interpolation algorithm as for voltages. 
This SPM analysis was used to ensure that the planned subsets of electrodes for hypothesistesting were sufficient to describe group differences measured at all 28 electrodes.

Based on the topographic pattern of left temporal P300 deficits in Morstyn et al. (1983) and Faux et al. (1988a, 1993) and the amplitude maxima of N400 and late positive components, a subset of electrodes were selected prior to statistical analysis. Specifically, we examined the mean integrated voltages at electrodes T.5, P3, Pz, P3, and T6. The MANOVA statistical analyses used paralleled our previous studies (Faux and McCarley, 1990). The MANOVA focused on between group differences, where Hotelling's $T^{2}$ test provided information on three kinds of differences: (1) overall group amplitude differences; (2) group amplitude differences at each scalp electrode site ('protected' $t$-contrasts); and (3) group topographic differences based on a test of a group-by-electrode-site interaction (profile analysis of parallelism). We also used McCarthy and Wood's (1985) algorithm for normalizing the data to eliminate amplitude differences which might be misinterpreted by MANOVA as an interaction.

\section{RESULTS}

\section{Behavioral performance}

During the week preceding the ERP test session, subjects were asked to verbally complete the final word of 80 sentences with known cloze probability $\geq 0.85$ based on the performance of elementary school children (from work of Holcomb and Neville, personal communication). The highest probability word was correctly supplied by schizophrenic subjects for an average of 76.6 of the 80 sentences, and by normal controls for 79.2 of the sentences.

In the context of the ERP design, response accuracy for judgments of the semantic appropriateness of sentence final words was reduced in schizophrenic when compared to control subjects (data based on 9/12 subjects per group due to software error and consequent data loss). The proportion of correct judgments was $0.87 \pm 0.15$ for the schizophrenic and 0.99 \pm 0.01 for the normal controls $(t(16)=15.02 ; p \leq 0.001)$. Patients' errors were distributed evenly among sentences with appropriate and inappropriate word endings.

\section{Event related brain potentials}

Fig. 1 presents the data at $\mathrm{PZ}$ and selected lateral sites for the semantically incongruent and semantically congruent final words. As shown, the N400 effect was produced in response to semantic incongruent words for both the schizophrenic and the normal controls. While the late positive component is evident in the waveform produced by the normal controls, it is virtually absent in the data from the schizophrenic subjects. Statistical analyses and all further presentation are based on the diflerence waveforms obtained by subtracting the semantically congruent condition waveform from the semantically incongruent condition waveform.

\section{Exploratory data analysis}

\section{Grand-averaged difference wave forms}

Fig. 2 displays the difference between anomalous and best fit condition wave forms. As shown, the general morphology and topography of the $\mathrm{N} 400$ component (approximately $250-500 \mathrm{~ms}$ ) and the late positive component (approximately $600-800 \mathrm{~ms}$ ) in normal subjects is in accord with studies by other investigators.

N400 Component latency at peak amplitude was examined at CZ, revealing a significant delay in the N400 in schizophrenics (at CZ: normal controls $=368.9 \pm 34.3 \mathrm{~ms}$; schizophrenics $=$ $393.1 \pm 23.3 \mathrm{~ms}, t(22)=2.02, p<0.056)$ relative to normal controls. The $\mathrm{N} 400$ latency delay in schizophrenia was not attributable to delays in earlier components. N100 and P200 peak 
latencies $(\mathrm{CZ})$ in the unsubtracted waveforms were not statistically different between schizophrenics and normal controls (mean N100 latencies = 134 and $127 \mathrm{~ms}$ respectively; mean P200 latencies $=194$ and $207 \mathrm{~ms}$, respectively). Additionally, no between-group latency difference was found for the late positive component.

\section{Grand-averaged component topography}

Fig. 3 shows the N400 component topography for normal controls and schizophrenics, and in the third panel the SPM, showing distribution of Mann-Whitney Z-scores resulting from between-group comparisons of integrated amplitudes at each scalp electrode site. Normal controls showed relatively symmetrical distribution of the N400 component, with maximal negativity in the centroparietal region. In contrast, schizophrenics appeared to show maximal negativity in the right temporal region, with less negativity in homologous left regions. The resultant Mann-Whitney Z-SPM shows a pattern of larger Z-scores on the left scalp than on the right, suggestive of, but not proving topographic asymmetry between groups.

Fig. 4 shows the late positive component topography for normal controls and schizophrenics, and the resultant Mann-Whitney Z-SPM. Again, these results reveal that normal controls had a relatively symmetrical distribution of the late positive component, with maximal positivity in the centroparieta1 region. In contrast, schizophrenics appear to show relatively symmetrical left/right voltage distributions, but with a posteriorly displaced maximum compared to normals. Again, the resultant Mann-Whitney Z-SPM shows a pattern of larger Z-scores on the left scalp than on the right, suggestive of, but not proving topography asymmetry between groups.

\section{Multivariate analyses using Hotelling's T-squared test}

\section{N400component}

Overall group difirences-Fig. 5 (left panel) plots the mean N400 amplitude values (by group and electrode site) which were used in the 'between-groups' MANOVA analyses. Overall N400 amplitude differences comparing schizophrenics (343-443 ms) and normal controls (319-419 ms) were statistically significant using an a priori MANOVA 'Levels' test (sum of amplitudes at $\mathrm{T} 5+\mathrm{P} 3+\mathrm{Pz}+\mathrm{P} 4+\mathrm{T} 6$ ), confirming the $\mathrm{N} 400$ amplitude reduction in schizophrenics compared to normal controls $(t(22)=2.29, p<0.05)$.

\section{Group amplitude differences at each scalp electrode site ('protected' Mann-} Whitney tests)-Protected Mann-Whitney contrasts comparing individual scalp regions were performed on the data in Fig. 5, left panel, by simply applying a Bonferroni correction. Electrodes with maximal statistical significance (at $P<0.05$ ) have been starred in the figure, indicating that $\mathrm{P} 3$ and $\mathrm{Pz}$ produced maximal statistical separation between groups, a finding consistent with the $t$-SPM topography.

Test of topographic interaction-As shown in Fig. 5, left panel, normal controls produced a relatively symmetrical voltage distribution, while schizophrenics showed slightly more negativity on the left than on the right. However, schizophrenic versus normal control group differences in normalized topographic distribution were tested by profile analysis of parallelism and found to be statistically non-significant $(F<1)$.

\section{Late positive component}

Overall group dzfirences-Fig. 5 (right panel) plots the mean amplitude values for the late positive component (by group and electrode site) which were used in the 'between-groups' MANOVA analyses. Overall amplitude differences (600-800 ms) comparing schizophrenics and normal controls were statistically significant (Hotelling's $T^{2}$ equivalent $F(5,18)=4.74$, $P<0.05$ ). A follow-up 'Levels' test (sum of amplitudes at T5 $+\mathrm{P} 3+\mathrm{Pz}+\mathrm{P} 4+\mathrm{T} 6$ ) statistically 
confirmed the overall late positive component reduction in schizophrenics compared to normal controls $(t(22)=3.87, P<0.001)$.

Group amplitude dzyerences at each scalp electrode site ('protected' MannWhitney tests)-Protected Mann-Whitney contrasts comparing individual scalp regions showed maximal statistical significance at $\mathrm{P} 3, \mathrm{Pz}$, and $\mathrm{P} 4$ electrode sites, which have been starred in Fig. 5, right panel.

Test of topographic interaction-As shown in Fig. 5, right panel, both normal controls and schizophrenics produced a relatively symmetrical voltage distribution, with a slight $L>R$ voltage distribution. This visual pattern does not suggest the presence of a group-by-scalp electrode site interaction. Indeed, schizophrenic versus normal control group differences in normalized topographic distribution were tested by profile analysis of parallelism and found to be statistically non- significant $(F(4,19)=1.36$, N.S. $)$.

\section{DISCUSSION}

In relation to normal controls, schizophrenic patients exhibited significantly attenuated amplitude and delayed latency for N400 to semantically incongruent sentence endings. These N400 abnormalities were also accompanied by significant group differences in amplitude but not for latency for the late positive component, with the schizophrenic patients again showing a significant reduction in amplitude, relative to normal controls. No group differences in the topography of the $\mathrm{N} 400$ or its late positive component were found. These current findings are thus consistent with other investigations that have demonstrated delayed N400 latency (Grillon et al., 1991; Hokama et al., 1990) and reduced N400 amplitude (Mitchell et al., 1992) in patients with schizophrenia.

The extent to which these schizophrenic N400 abnormalities reflect a specific impairment in semantic processing is, however, unclear. Indeed, amplitude reductions were evident for both the presumably semantically sensitive N400 as well as its late positive component, which is thought not to be strongly related to semantic operations. This suggest that the demonstrated ERP abnormalities in the current sample of schizophrenic patients may reflect a more general diminution in attentional resources rather than a specific impairment in processing semantic incongruities. Mitchell et al. (1991), who recently conceptualize the N400 and its late positive potential in terms of the distinction between passive and active attentional processes, suggested the N400 reflects a passive, automatic semantic priming mechanism, whereas its last positive potential reflects an active, voluntary, and conscious process. The current results therefore point to a functional impairment in both so-called automatic and controlled processes of attention in this group of schizophrenic patients.

That these current data may reflect an impairment in both automatic and controlled processes of attention is somewhat of a departure from behavioral studies that typically find that controlled but not automatic attentional processes are compromised by schizophrenia (Kwapil et al., 1991; Nestor et al., 1990, 1991, 1992; Oltmanns, 1978). In fact, Callaway and Naghdi (1982) suggested that automatic processes may be normal or supernormal in schizophrenia. However, the current group of patients have a mixed positive and negative symptom profile with a markedly severe and chronic illness that has had a widespread and debilitating effect on a variety of mental processes, regardless of whether these may be characterized as automatic or controlled in nature. Future studies will need to address the effect of chronicity on the N400 in patients with schizophrenia. Likewise, the effects of neuroleptic medications on N400 are unknown and are worthy of further study. 
The neural generators that may underlie the N400 deficit in schizophrenia are also unknown. In contrast, evidence from depth electrode studies in patients with seizure disorders suggest P300 generators in medial temporal lobe, while studies of stroke lesions suggest that the superior temporal gyrus lobe plays a critical role in the P300 circuit. Recent data from our laboratory (McCarley et al., 1993) point to a strong linkage between P300 asymmetry and volume reductions of the left posterior STG in schizophrenics. Because the topography of the $\mathrm{N} 400$ component differs from that of $\mathrm{P} 300$, and no topographic asymmetry is observed in schizophrenic patients, it is possible that the N400 deficit in some schizophrenics reflects a disturbance of a different neurobehavioral system than the P300 component.

In summary, the present study underscores the utility of the $\mathrm{N} 400$ as a physiological probe of cognitive operations involved in thought in both patients and controls. Future studies are needed to examine the relationship of the $\mathrm{N} 400$ and its late positive potential in schizophrenia with specific objective clinical measures of thought disorder, and to examine the N400 in unmedicated patients. Moreover, it would also be instructive to examine the relationship of N400 and auditory P300 in the same groups of schizophrenic patients, and to determine which MRI-defined abnormalities can be associated with the N400. In a similar vein, future studies may also want to address $\mathrm{N} 400$ within the auditory modality. The P300, for example, varies considerably as a function of modality in schizophrenia, with auditory P300 amplitude consistently depressed (Pritchard, 1986) especially over left temporal scalp regions (Faux et al., 1990), whereas visual P300 amplitude is not consistently depressed (Pfefferbaum et al., 1989; Wagner et al., 1990). Nevertheless, the present study reinforces the usefulness of the N400 as yet another important neurophysiological probe in schizophrenia, and one that is particularly cogent because of its potential relationship to the hallmark symptom of thought disorder.

\section{Acknowledgments}

Supported by the Veterans Administration Medical Research Service, NIMH 40,799, the Commonwealth of Massachusetts Research Center, the National Alliance for Research on Schizophrenia and Depression (NARSAD), the Scottish Rite Foundation, the Stanley Foundation, and NIMH KO1 MH 00746-05.

\section{REFERENCES}

Adams, J.; Faux, SF.; McCarley, RW., et al. The N400 and language processing in schizophrenia.. Proceedings of the 9th International Conference on Event Related Potentials of the Brain (EPIC IX); 1989. p. 12-13.

American Psychiatric Association, Committee on Nomenclature and Statistics. Diagnostic and Statistical Manual of Mental Disorder, Revised. Third Edition. American Psychiatric Association; Washington, D.C.: 1987.

Andreasen NC. Thought, language and communication disorders. I. Clinical assessment, definition of terms, and evaluation of their reliability. Arch. Gen. Psychiatry 1979a;36:1315-1321. [PubMed: 496551]

Andreasen NC. Thought, language and communication disorders. II. Diagnostic significance. Arch. Gen. Psychiatry 1979b;36:1325-1330. [PubMed: 496552]

Andreasen, NC. Scale for the Assessment of Negative Symptoms (SANS). University of Iowa College of Medicine; Iowa City: 1981.

Andreasen, NC. Scale for the Assessment of Positive Symptoms (SAPS). University of Iowa College of Medicine; Iowa City: 1984.

Andreasen NC, Grove WM. Thought, language and communication in schizophrenia: diagnosis and prognosis. Schizophr. Bull 1986;12:348-359. [PubMed: 3764356]

Bentin S, McCarthy G, Wood CC. Event-related potentials associated with semantic priming. Electroencephalog. Clin. Neurophysiol 1985;60:343-355. 
Buchsbaum MS, Rigal F, Coppola R, et al. A new system for gray-level surface distribution maps of electrical activity. Electroencephalog. Clin. Neurophysiol 1982;53:237-242.

Callaway E, Naghdi S. An information processing mode1 for schizophrenia. Arch. Gen. Psychiatry 1982;39:339-347. [PubMed: 7065844]

Duffy, FH. Topographic display of evoked potentials: clinical applications of brain electrical activity mapping (BEAM).. In: Bodis-Wollner, I., editor. Annals of the New York Academy of Sciences. New York Academy of Sciences; 1982. p. 183-196.

Duffy FH, Bartels PH, Burchfiel JL. Significance probability mapping: an aid in the topographic analysis of brain electrical activity. Electroencephalog. Clin. Neurophysiol 1981;51:455-462.

Faux SF, McCarley RW. Analysis of scalp voltage asymmetries using Hotelling's T-squared methodology. Brain Topogr.: Journal of Functional Neurophysiology 1990;2:237-245.

Faux SF, McCarley RW, Nestor PG, et al. P300 topographic asymetries are present in unmedicated schizophrenics. Electroencephalography and Clinical Neurophysiology 1993;88:32-41. [PubMed: 7681389]

Faux SF, Shenton ME, McCarley RW, et al. Differentiation of schizophrenics and normal controls is enhanced by the Goodin subtraction procedure. Int J of Neuroscience 1988a;39:117-135.

Faux SF, Torello MW, McCarley RW, et al. P300 in schizophrenia: confirmation and statistical validation of temporal region deficit in P300 topography. Biol Psychiatry 1988b;23:776-790. [PubMed: 3365456]

Fischler I, Bloom P, Childers DG, et al. Brain potentials related to stages of sentence verification. Psychophysiology 1983;20:400-409. [PubMed: 6356204]

Grillon C, Ameli R, Glazer WM. N400 and Semantic categorization in schizophrenia. Biol. Psychiatry 1991;29:467-480. [PubMed: 2018820]

Hoffman RE, Stopek S, Andreasen NC. A comparative study of manic vs schizophrenic speech disorganization Arch. Gen. Psychiatry 1986;43:831-838.

Hokama, H.; Koyama, S.; Miyatani, M., et al. Abnormality of contextual effect on ERPs in schizophrenia and N400 topography.. In: Brunia, CHM.; Gaillard, AWK.; Kok, A., editors. Psychophysiological Brain Research. Vol. 2. Tilburg UP: 1990. p. 213-217.

Holzman PS, Shenton ME, Solovay MR. Quality of thought disorder in differential diagnosis. Schizophr. Bull 1986;12:360-371. [PubMed: 3764357]

Johnson, MH.; Holzman, PS. Assessing Schizophrenic Thinking. Jossey-Bass; San Francisco: 1979.

Kutas M, Hillyard SA. Reading senseless sentences: brain potentials reflect semantic incongruity. Science 1980;207:203-205. [PubMed: 7350657]

Kutas M, Hillyard SA. Brain potentials during reading reflect word expectancy and semantic association. Nature 1984;307:161-163. [PubMed: 6690995]

Kutas, M.; Lindamood, T.; Hillyard, SA. Word expectancy and event-related brain potentials during sentence processing.. In: Kornblum, S.; Requin, J., editors. Preparatory States and Processes. Erlbaum; Hillsdale, NJ: 1984.

Kutas, M.; Neville, HJ.; Holcomb, PJ. Ellingson, RJ.; Murray, NMF.; Halliday, AM., editors. A preliminary comparison of the N400 response to semantic anomalies during reading, listening, and signing.; The London Symposium (EEG Suppl. 39). 1987. p. 325-330.

Kwapil TR, Hegley DG, Chapman LJ, Chapman JP. Facilitation of word recognition by semantic priming in schizophrenia. J. Abnormal Psychol 1990;99:215-221.

McCarley RW, Faux SF, Shenton ME, et al. CT Abnormalities in Schizophrenia. Arch. Gen. Psychiatry 1989;46:698-708. [PubMed: 2751404]

McCarley RW, Faux SF, Shenton ME, et al. Event-related potentials in schizophrenia: their biological and clinical correlates and a new model of schizophrenic pathophysiology. Schizophr. Res 1991;4:209-231. [PubMed: 2039762]

McCarley RW, Shenton ME, O'Donnell BF, et al. Auditory P300 abnormalities and left posterior superior temporal gyrus volume reduction in schizophrenia. Arch. Gen. Psychiatry 1993;50:190-197. [PubMed: 8439239]

McCarthy G, Wood CC. Scalp distributions of event-related potentials: an ambiguity associated with analysis of variance models. Electroencephal. Clin. Neurophysiol 1985;62:203-208. 
Mitchell PF, Andrews S, Fox AM, Catts SV, Ward PB, McCognaghy N. Active and passive attention in schizophrenia: An ERP study of information processing in a linguistic task. Biol. Psychol 1991;32:101-124. [PubMed: 1790265]

Morstyn R, Duffy FH, McCarley RW. Altered P300 topography in schizophrenia. Arch. Gen. Psychiatry 1983;40:729-734. [PubMed: 6860074]

Nestor PG, Faux SF, McCarley RW, Shenton ME, Sands SF. Measurement of visual sustained attention using a newly developed computerized CPT task. Schizophr. Res 1990;3:329-332. [PubMed: 2282338]

Nestor PG, Faux SF, McCarley RW, Sands SF, Horvath TB, Peterson A. Neuroleptics improve sustained attention in schizophrenia. A study using signal detection. Neuropsychopharmacology 1991;3:1-5.

Nestor PG, Faux SF, McCarley RW, Penhune V, Shenton ME, Pollak S, Sands SF. Attentional cues in chronic schizophrenia: abnormal disengagement of attention. J. Abnorm. Psychol 1992;101:682689. [PubMed: 1430608]

Oltmanns T. Selective attention in schizophrenic and manic psychoses: the effect of distraction on information processing. J. Abnorm. Psychol 87:212-225. [PubMed: 649860]

Pfefferbaum A, Ford JM, White PM, Roth WT. P3 in schizophrenia is affected by stimulus modality, response requirements, medication status, and negative symptoms. Arch. Gen. Psychiatry 1989;46:1035-1044. [PubMed: 2573328]

Pritchard WS. Cognitive event-related potential correlates of schizophrenia. Psychol. Bull 1986;100:4366. [PubMed: 2874579]

Semlitsch HV, Anderer P, Schuster P, et al. A solution for reliable and valid reduction of ocular artifacts, applied to the P300 ERP. Psychophysiology 1986;23:695-703. [PubMed: 3823345]

Shenton ME, Kikinis R, Jolesz FA, et al. Abnormalities of the left temporal lobe and thought disorder in schizophrenia: a quantitative magnetic resonance imaging study. N. Eng. J. Med 1992;327:604-612.

Spitzer, RL.; Endicott, J.; Robins, E. Research Diagnostic Criteria for a Selected Group of Functional Disorders. Ed 3.. Biometrics Research Division, New York State Psychiatric Institute; New York: 1977.

Wagner, Gabriele K, Engle RR. Normal P300 in acute schizophrenics during a continuous performance task. Biol. Psychiatry 1989;25:788-792. [PubMed: 2629711] 

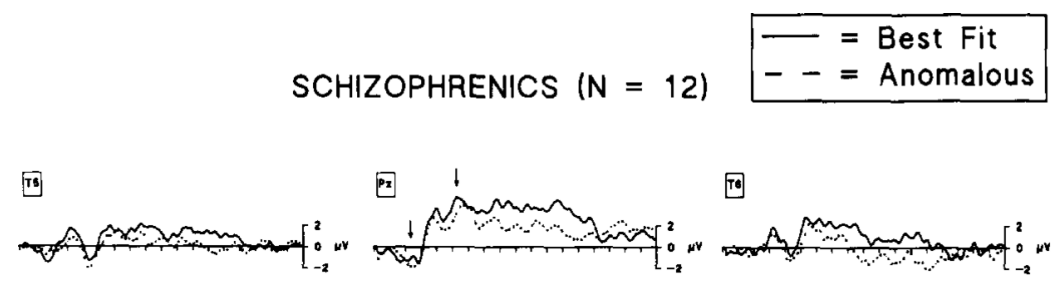

NORMAL CONTROLS $(N=12)$

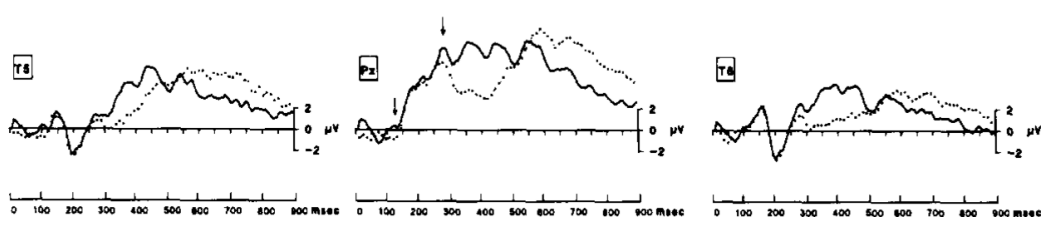

Fig. 1.

Grand-averaged waveforms elicited by 'best fit' (continuous line) and 'anomalous' (dashed line) end-of-sentence words in schizophrenics (top) and normal controls (bottom). In normal controls, note that the waveform associated with the 'anomalous' condition showed increased negativity (N400) in the $300-500 \mathrm{~ms}$ range and increased positivity (late positive component) in the 600-800 ms range with respect to the waveform associated with the 'best-fit' condition. Note, further, that these respective negativities and positivities in schizophrenics are negligible relative to normal controls. Voltage levels at time zero (baselines) were determined by the mean of a $100 \mathrm{~ms}$ prestimulus interval (not shown). Arrows (at Pz) indicate the approximate position of the mean N100 and P200 peak component latencies, respectively. Mean latency differences for these early components between groups were not statistically different. For both groups, $n=12$. 

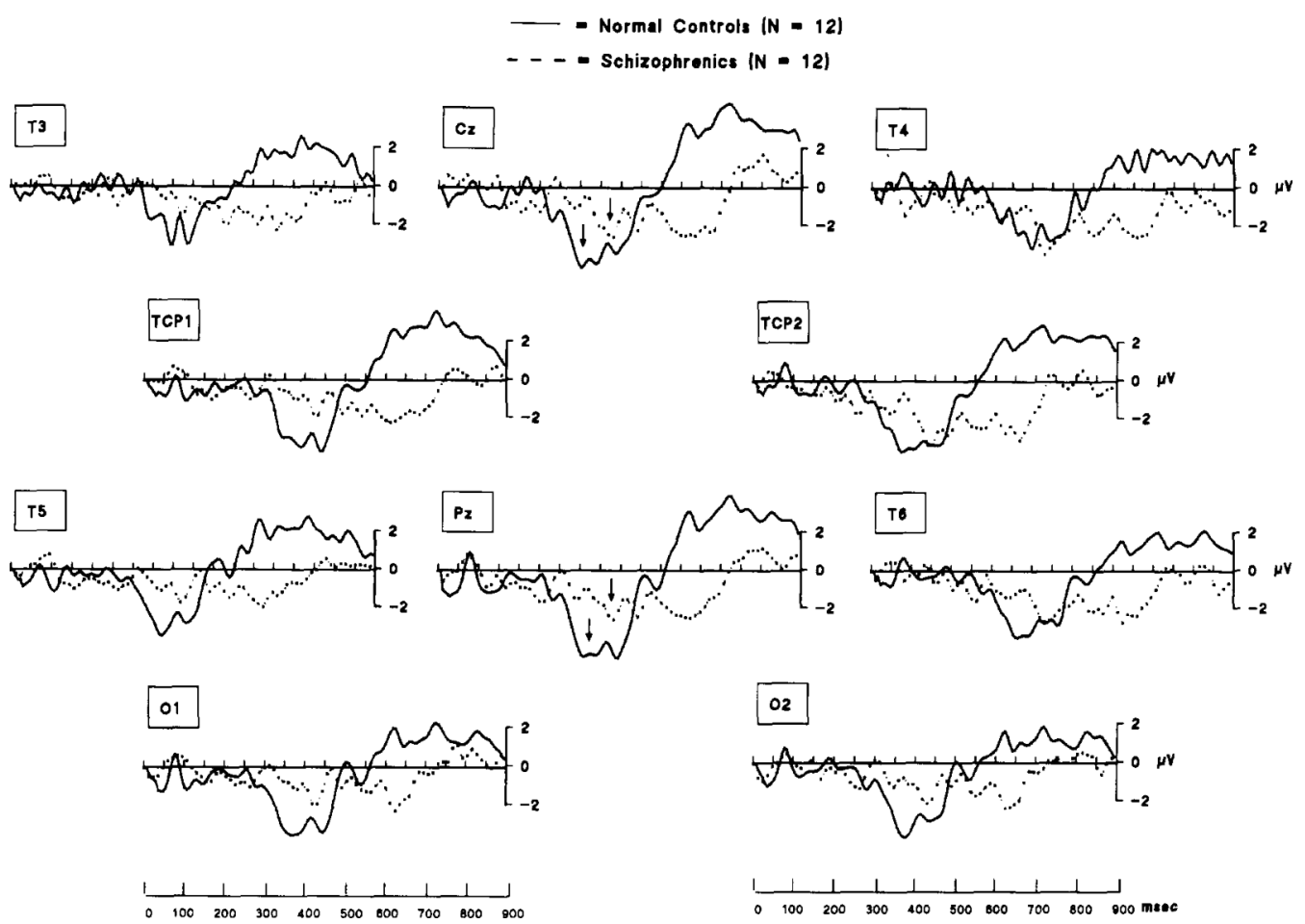

Fig. 2.

Grand-averaged difference waveforms ('anomalous' minus 'best-fit') for schizophrenics ( $\mathrm{n}=$ 12 , continuous lines) and normal controls ( $\mathrm{n}=12$, dashed lines). In normal controls, increased negativity (N400) was apparent in the 300-500 ms range, but is negligible for schizophrenics. Normal controls showed increased positivity (late positive component) in the 600-300 ms range; schizophrenics showed virtually no positivity in this time range. Arrows (at $\mathrm{Cz}$ and $\mathrm{Pz}$ ) indicate the approximate position of the mean N400 peak component latencies for both schizophrenic patients and normal controls. Group latency differences were statistically significant. 


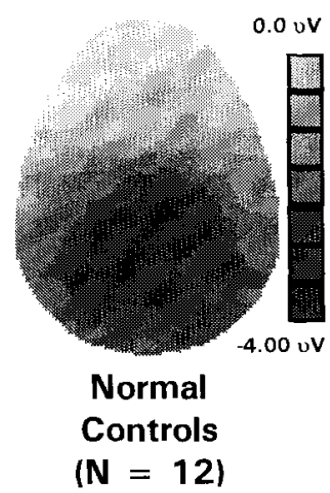

319-419 msec

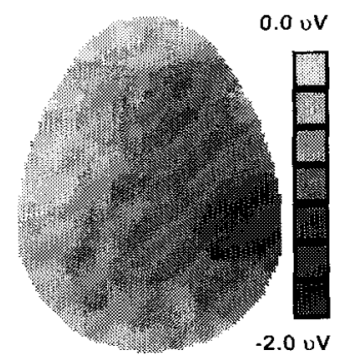

Schizophrenics

$(\mathrm{N}=12)$

343-443 msec

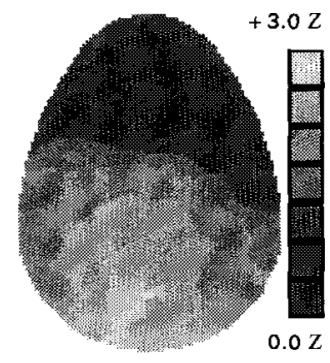

Mann -

Whitney

$\mathbf{Z}$

Fig. 3.

Topographic distribution of N400 component activity (319-419 ms in normal controls and 343-443 ms in schizophrenics) and Mann-Whitney Z-SPM. Left and middle panels: These voltage maps show that normal controls produced a relatively symmetrical pattern of negativity (darker greys equal greater negativity), with a posterior minima at the midline. By contrast, schizophrenics showed a slightly greater negativity over right scalp than left. Grey-coded voltages are scaled differently for schizophrenics and normal controls to make scalp distributions clearly visible. Voltage scale maxima and minima are the following: normal controls $=0.0$ to $-4.0 \mu \mathrm{V}$; schizophrenics $=0.0$ to $-2.0 \mu \mathrm{V}$. Right panel, SPM: scale maxima and minima were the following: $Z=+3.0$ to 0.0 . The largest $Z$-values were in the left temporaloccipital scalp region (TCP1, P3, 01) with $Z$-values ranging from 2.02 to 2.60 . The $Z$-values of neighboring centro-temporal electrodes (T3, C3, Cz, C4, T4) were 0.02 to 1.76. 

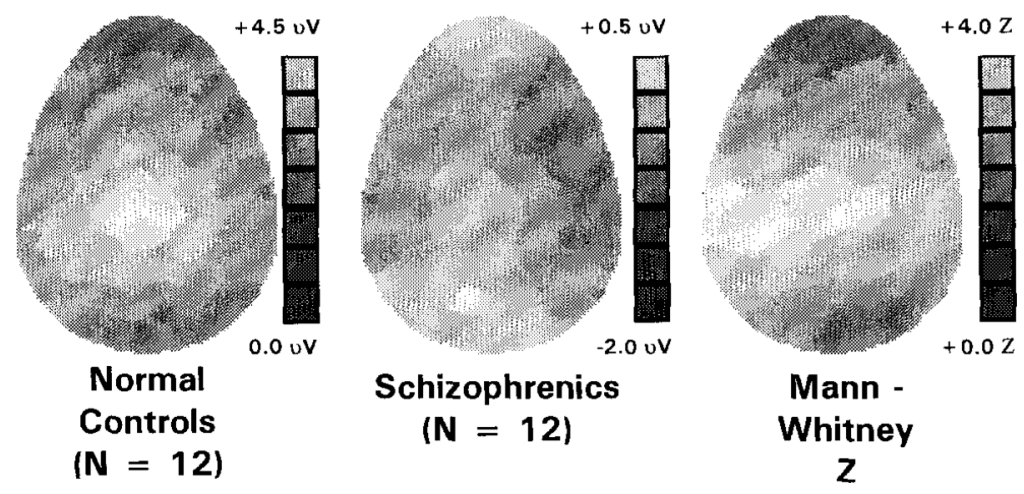

Fig. 4.

Topographic distribution of late positive component (600-800 ms) and Mann-Whitney Z-SPM. Left and middle panels: Voltage maps show that normal controls produced a relatively symmetrical pattern of positivity (lighter greys equal greater positivity), with a posterior maximum at the central midline (lightest grey). By contrast, schizophrenics showed their greatest positivity over left occipital scalp. Grey-coded voltages are scaled differently for schizophrenics and normal controls to make scalp distributions clearly visible. Voltage scale maxima and minima are the following: normal controls $=4.5$ to $0.0 \mu \mathrm{V}$; schizophrenics $=+0.5$ to $-2.0 \mu \mathrm{V}$. Right panel, SPM: scale maxima and minima were the following: $Z=+4.0$ to 0.0 . The largest $Z$-values were in the left temporal scalp region (T3, TCP1, C3, Cz), with $Z$-values ranging from 3.61 to 3.90 . The $Z$-values of neighboring electrode sites ranged from 0.92 to 3.70 . 
N400 COMPONENT

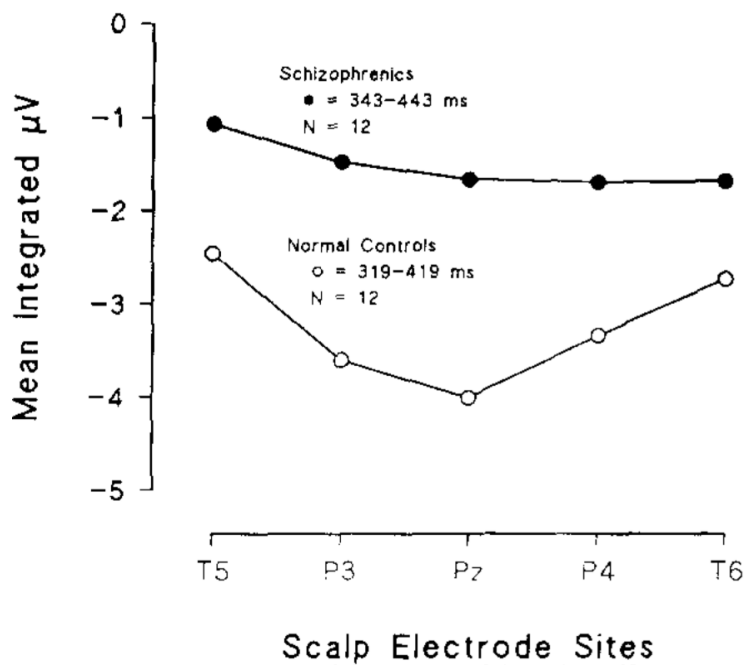

LATE POSITIVE COMPONENT

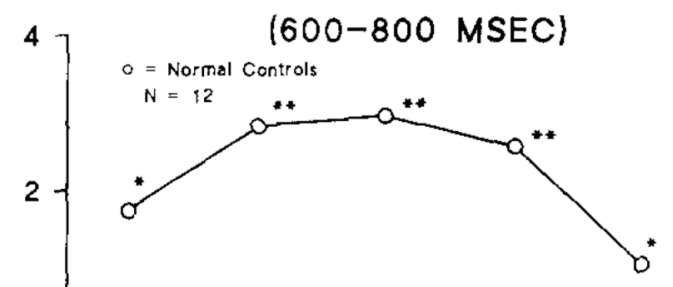

- Schizophrenics

$N=12$

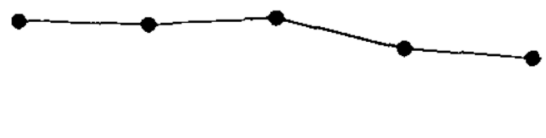

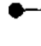

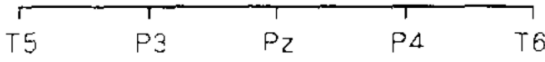

Scalp Electrode Sites

Fig. 5.

Mean integrated N400 (left panel) and late positive component (right panel) amplitude compared by groups and scalp recording region. Despite large amplitude differences between groups, note that both groups showed amplitudes that were relatively symmetrical about the midline (Pz). Statistical differences (Bonferroni-corrected) of between-group amplitude differences by electrode site are asterisked $(p<0.05)$. 